\title{
Fixing the Fix for Silver and Gold
}

\author{
Susan J. Crain, Seth A. Hoelscher, Jeffrey S. Jones*
}

Missouri State University

\section{ARTICLE INFO}

\section{Article history:}

Received 25 August 2020

Revised 05 October 2020

Accepted 16 October 2020

Published 06 November 2020

\section{Keywords:}

Futures markets

Gold

Price Fixing

Spot markets

Silver

JEL Classification: G13; G14; G15

\begin{abstract}
Accusations of price manipulation in the silver and gold markets have emerged in recent years. In an effort to increase transparency, the London spot price "fixing" mechanism was recently changed from an opaque negotiation process among a small number of dealer banks to a more observable auction platform system with more participants and public reporting. This change in the price fixing process raises questions about whether manipulation was occurring prior to the fix change and whether any perceived manipulation has since been reduced. Our results suggest that the changes to the price fixing process have impacted volatilities and prices within the silver and gold markets which could be an indicator of manipulation prior to the change.
\end{abstract}

\section{Introduction}

In March of 2014, a class action complaint was filed in the Southern District Court of New York against the participating banks involved in the London gold fix. The complaint alleged price fixing by the banks in order to benefit on proprietary trading positions in the futures market. The court filing included extensive analysis by Rosa Abrantes-Metz who had previously examined the Libor market for manipulation as well as other markets for collusion. The defendants included The Bank of Nova Scotia, Barclays Bank PLC, Deutsche Bank Ag, HSBC Bank PLC, Société Générale, and London Gold Market Fixing Ltd. She concluded that her findings in the gold market were consistent with the possibility of collusion. An additional market analysis was provided in the court filing by Andrew Caminschi, a gold market researcher who has published in the field (e.g., Caminschi \& Heaney, 2014). His conclusions were also suggestive of manipulation.

Rice (2014) notes in the Financial Times that U.S. lawyers filed a minimum of three class action lawsuits in March 2014 alleging price manipulation in the gold market. Furthermore, Burne, Day, and Shumsky (2013) note in a Wall Street Journal article that the Commodity Futures Trading Commission (CFTC) was also investigating the setting of gold prices in London. The court filings and CFTC investigation occurred prior to the change in the fixing process in silver and gold and were likely precipitated by the Libor scandal. It is also likely that the Libor scandal was instrumental in leading to the price fixing change in the London metal markets.

An opaque price setting process potentially allows for easier price manipulation as well as being harder to detect. Furthermore, the statistical evidence provided in the class action lawsuits was sufficient to raise the possibility of impropriety. The purpose of this study is to examine pricing patterns in the spot and futures contracts in the periods prior to and following the London fix changes for silver and gold to detect evidence of manipulation that may have been reduced due to the increased transparency of the fixing process.

* Corresponding author.

E-Mail address: JeffSJones@MissouriState.edu

ORCID: 0000-0003-0851-5407 
We begin this process by providing a history of the fixing processes for both silver and gold. We then summarize the prior relevant literature, and develop testable hypotheses. We collect pricing data from the silver and gold spot and futures markets, and examine the changes in both returns and volatilities between the pre-fix change and post-fix change periods. Though no meaningful differences in returns are observed, we find structural changes in volatility post-fix change in both silver and gold markets, and use a number of empirical procedures to examine and document these changes. Finally, we discuss our findings, and possible implications to other financial markets.

\section{The Fixing Process}

Information for this section obtained from the London Bullion Market Association (LBMA) website (London Bullion Market Association, 2017).

\section{History of the Silver Fix}

In 1897, the London Bullion Market instituted the first silver price "fix," whereby four prominent trading companies of the time established the daily spot price through a negotiation process based on buy and sell orders. Likewise, the first London gold "fix" occurred in 1919 through a similar process with five companies involved. Except for a few trading halts due to major macroeconomic events, the essential mechanism of the fixes remained in place until 2014 for silver and 2015 for gold. According to the London Bullion Market Association, the recent change in the silver fix increased transparency and provides a process that is compliant with guidelines established by the International Organization of Securities Commissions (IOSCO).

Prior to the change to the London silver fix process on August 15, 2014, only three dealer banks participated in the daily price negotiation of silver: Deutsche Bank AG, HSBC Holdings PLC, and The Bank of Nova Scotia. With the 2014 change in the silver fix process, the number of accredited players increased to seven: China Construction Bank, HSBC Bank USA NA, JPMorgan Chase Bank, Morgan Stanley, The Bank of Nova Scotia - ScotiaMocatta, The Toronto Dominion Bank, and UBS AG. The number of participating members in the silver price fixing should continue to increase over time as more banks, trading houses, refiners, and producers obtain accreditation. There are currently twelve accredited participants contributing to the LBMA silver price according to the LBMA (London Bullion Market Association, 2020c).

The current silver pricing process includes an auction platform provided by the Chicago Mercantile Exchange (CME) group with Thomson Reuters taking responsibility for the administration and governance of the LBMA silver price. CME and Thomson Reuters terminated the administration of the silver fix in 2017. Effective September 25, 2017, Intercontinental Exchange (ICE) Benchmark Administration (IBA) took over the operation of the auction process for the silver fix. All participants in the auction are required to sign Thomson Reuter's Code of Conduct that is based on IOSCO principles. The daily process consists of a series of electronic auction rounds starting at noon (12:00 London BST), during which each participant is required to input their buy volume and sell volume orders. In the first round with the initial price close to the current spot price, the system algorithm attempts to match buy and sell orders within a permitted tolerance level of volume. If the buy and sell orders are outside the tolerance range, the auction price adjusts, and another auction round is initiated. This iterative process continues until the buy and sell order volumes are within the acceptable tolerance range and the new equilibrium price is set. Thomson Reuters distributes the LBMA silver price in real-time through market data systems and also provides access through redistribution via third-party data vendors such as Bloomberg and Fastmarkets.

\section{History of the Gold Fix}

The change in the gold fix occurred on March 20, 2015, when the new auction platform replaced the twice-daily telephone conference fixing process by five market participants: Barclays, Deutsche Bank, HSBCV, The Bank of Nova Scotia - ScotiaMocatta, and Societe Generale. The new pricing mechanism consists of an auction platform provided by Intercontinental Exchange Benchmark Administration (IBA), with IBA also providing independent administration and governance. The LBMA gold price is set twice daily at 10:30 a.m. and 3:00 p.m. (London BST). The gold price is available from many data vendors and redistributors. Also, the live auction feed is available via Reuters and Bloomberg.

The new process consists of the chairperson setting the starting price and the price for each subsequent round of the auction according to current market conditions and activity. Like the silver fix, participants enter their buy and 
sell orders by volume and, if the net volume falls within the pre-determined tolerance at the end of a round, the auction is complete and all volume is tradeable at that price. At the end of the auction process, IBA publishes the benchmark price as well as a Transparency Report showing the price, the aggregated bid and offer volume, the number of participants, and the timings for each round. The accredited price participants for the current gold fix include: Bank of China, Bank of Communications, Coins 'N Things, Goldman Sachs International, HSBC Bank USA NA, Industrial and Commercial Bank of China (ICBC), INTL FCStone, Jane Street Global Trading LLC, JP Morgan Chase Bank NA London Branch, Koch Supply and Trading LP, Marex Financial Limited, Morgan Stanley, Standard Chartered Bank, The Bank of Nova Scotia, and The Toronto Dominion Bank. There are currently fifteen accredited participants contributing to the LBMA gold price reported by the LBMA (London Bullion Market Association, 2020b).

\section{Summary}

The historical processes of the silver and gold fixes suggest opportunities for anti-competitive collusion and manipulation, as the process has been historically opaque with very few participants. In the section that follows, we summarize the findings of prior studies that examine instances of pricing behaviors between competitive and anticompetitive periods, as well as studies regarding specific pricing behavior in silver and gold markets.

\section{Prior Literature and Hypotheses}

\section{Detecting Manipulation}

Several collusion/cartel schemes have occurred in the past that provide a state of conditions that allow researchers to examine the difference in pricing behaviors between competitive and anti-competitive periods. Studies in this arena intend to develop screening mechanisms that allow regulators and harmed parties to detect incidences of collusive behavior in the future. For instance, Genesove and Mullin (2001) examine pricing behavior during the lifetime of a sugar-refining cartel to discover decreased variances of profit margins. In a study of known bid-rigging behavior among seafood processors, Abrantes-Metz, Froeb, Geweke, and Taylor (2006) observed that price levels decreased while standard deviations increased following the collapse of the conspiracy. Thus, the authors suggest utilizing both components in the coefficient of variation as a screening method for detecting collusion. The authors describe other studies that document decreased variances when collusion is in place, including Bolotova, Connor, and Miller (2008) and Genesove and Mullin (2001). Bolotova et al. (2008) utilize data from incidents of documented collusion in lysine and citric acid markets to develop screens based on the first two moments of the price distribution in ARCH and GARCH models. They argue that the simultaneous estimation of mean and variance is an improvement to the coefficient of variation used by Abrantes-Metz et al. (2006).

In a separate study, Abrantes-Metz and Addanki (2007) consider the Hunt Brothers' manipulation of the silver market in 1979-80 to develop a screen based on the ability of futures prices to forecast future spot prices. They argue that manipulation in the futures markets does not allow the price to achieve its correct value leading to larger variances of the forecasting errors. Concerning the mean values of the forecasting errors, they are expected to be larger or smaller depending on whether prices are being manipulated higher or lower. Finally, a different type of analysis is conducted by Abrantes-Metz, Villas-Boas, and Judge (2011) who examine the London Interbank Offer Rate and consider Benford's law, which is a mathematical formula that has been shown to describe naturally occurring patterns in the distribution of digits in data series. Violation of the law potentially serves as a screening device for manipulation/collusion.

Other studies have examined markets where manipulation had not been previously documented. For instance, Drudi and Massa (2005) explore the Italian Treasury bond market where parallel trading occurs in a transparent secondary futures market as well as a more opaque primary market. The authors suggest that with asymmetric information, informed dealers can exploit informational advantage by manipulating prices in the transparent market to induce erroneous beliefs that will then impact the primary market in which they will also be trading. Specifically, they will sell in the secondary market and place bid orders in the primary market. After the primary market has closed, they then repurchase in the secondary market. Any losses incurred in the secondary market manipulation are offset against gains in the primary market. 


\section{Evidence in the Gold and Silver Markets}

As mentioned previously, Abrantes-Metz and Addanki (2007) developed a screen using the Hunt Brothers' manipulation episode in the silver market with evidence pointing to larger variances of the forecasting errors for futures contracts. In addition, the price of silver bullion was driven much higher through the Brothers' purchases of futures contracts and the market moved from a position of contango (futures prices exceed spot prices) to a position of normal backwardation (spot prices exceed futures prices) during the manipulation period due to an artificially low supply of the physical silver relative to the futures position.

In a different type of analysis, Batten, Lucey, and Peat (2016) focus on "run manipulation" whereby an informed investor takes a position in the market and then moves the price in a profitable direction by attracting new uninformed investors. The authors examine the distributional properties of spot gold and silver (Forex trade codes: XAU and XAG, respectively) over the sample period of January 1, 2010, through April 30, 2015, to determine if a random walk or geometric Brownian motion applies, indicative of weak form market efficiency. Although the authors find anomalous behavior in both gold and silver, they conclude that volatility is responsible for the abnormal cluster rather than price manipulation. It is worth noting, however, that the sample period for their study includes a mixed sample that includes dates before and after the change to the London fix procedure.

Caminschi and Heaney (2014) utilize intraday data surrounding the London PM gold fix to determine its impact on price, trading volume and volatility of the gold futures contracts traded at the Chicago Mercantile Exchange (CME). They also examine the impact of the gold fix on the State Street Global Advisors Gold Exchange-Traded Fund (Ticker: GLD). The authors document that both markets exhibit significant increases in volume and volatility at the start of the price fixing process in the afternoon (3:00 p.m. London time). Ultimately, the authors conclude that there appears to be information leaking from the fixing prior to the final publication of the fixed price. The sample period used by Caminschi and Heaney (2014) includes only data prior to the changing of the London fix procedure.

Nilsson (2015) also considers the gold fix and further explores the fix change that occurred in 2015. He documents futures prices exhibit a large decline ahead of the morning fix and prices increase following the afternoon fix. However, he concludes through graphical analysis that price patterns are similar after the fix change of 2015 was instituted. Nilsson also examines the silver market fix change in 2014 using similar techniques. He notes negative price pressure going into the fix and positive price pressure following the fix using graphical analysis. Regarding the fix change, he concludes that price moves are similar but there was a greater level of volatility before the change in 2014.

The final stream of relevant literature discussed here concerns the linkages between the various spot markets with exchange-traded futures markets and funds. In an intra-day analysis of gold in the London over-the-counter market (LOTC) and Globex futures, Hauptfleisch, Putninšs, and Lucey (2016) conclude that the futures market consistently leads the spot in price discovery, consistent with the findings of Liu and Chou (2003). Using daily data, Lucey, Larkin, and O'Connor (2013) conclude that the London AM fix price in gold informs the COMEX futures close but that the futures close also informs the following day's London AM fix. The authors conjecture that price discovery is unstable with evidence of shifting causal relationships related to major macroeconomic and financial events.

\section{Summary}

Research shows that the price fix in the gold and silver markets is an economically important event, as volume and volatility of related products spike in the moments surrounding the price-fixing process. Drudi and Massa (2005) also show that informed traders can benefit by trading in parallel markets that exist for the banks involved in the London fix. Indeed, the evidence provided by Abrantes-Metz and Caminschi in the class action lawsuit in 2014 suggests that unusual trading patterns existed in the spot gold market where unexplained large downward price spikes occur at the time of the afternoon price fix but not the morning price fix. Furthermore, intraday returns in the futures market show that the only intervals throughout the London trade day with significantly negative returns coincide with the afternoon fix.

Collectively, these conclusions suggest that an investigation into the impact of the recent changes in the price fix processes for gold and silver is a worthy endeavor. Although prior studies have focused on intraday data with particular attention to the minutes and hours immediately surrounding the fix times in London, we examine prices at the open and close of trading in the futures markets because it seems conceivable that manipulation opportunities would exist throughout the trading day and might be more desirable in less scrutinized periods. Pirrong (2017) mentions allegations of trade-based manipulation in the gold and silver markets because the fixes in the two markets are used to settle derivatives transactions. He further describes a model developed by Kumar and Seppi (1992) based 
on temporal asymmetry in the information environment whereby a manipulator can place a derivatives position at the initiation of a contract without causing large movements in price because liquidity is high and informed trading is scant. Then at the time of settlement of the derivative, the manipulator will trade in the underlying asset in the same direction as the derivative. Because informed trading is now high and liquidity is reduced, there is an increased sensitivity of prices because market makers are protecting themselves against the better informed. This will move the derivatives price to the manipulator's advantage.

We believe that the underlying principles of this argument could potentially apply on a daily basis where the price fixing participants could place derivatives trades at the open/close of a futures contract on any given day when informed trading is at a low level relative to the period surrounding the fixes themselves. Thus, their trades would have a small impact on derivative prices. The direction of their trades (long or short) would presumably be tied to the inside information they possess concerning buy and sell orders to be processed during the price fix later in the day. If greater transparency in the fixing process has eliminated or reduced derivatives trades by these informed traders at the open/close of the futures contract, this should serve to increase liquidity and reduce price sensitivity. Specifically, we propose a test of the Kumar and Seppi (1992) model is as follows:

Hypothesis 1: If prices were manipulated prior to the fix change, then volatilities in the futures market will decrease in the post fix change period.

Alternatively, the previously mentioned examinations of collusion/cartel behavior by Genesove and Mullin (2001) and Abrantes-Metz et al. (2006) suggest that if the fix participants were sharing information in a coordinated effort to manipulate prices while simultaneously trading in the futures market, an opposite result from Kumar and Seppi (1992) will follow in the aftermath of the fix change with accompanying increased transparency. Thus, a competing hypothesis is:

Hypothesis 2: If prices were manipulated prior to the fix change, then volatilities in the futures market will increase in the post fix change period.

The final strategy for detecting manipulation focuses on the use of Benford's Law as suggested by Abrantes-Metz et al. (2011). The manipulation of prices will presumably not allow the digits of the prices to approach a natural order and the hypothesis is as follows:

Hypothesis 3: If prices were manipulated prior to the fix change, then violations of Benford's Law will be more prevalent in the earlier sub-period.

In the next section, we discuss market infrastructure characteristics of silver and gold spot and futures markets, as well as the process of collecting of specific empirical data used to test the above stated hypotheses.

\section{Market Infrastructure and Data}

\section{Market Infrastructure}

\section{London Spot Market}

The precious metals market consists of a physical market where the actual commodity is exchanged, as well as a paper market where the physical asset may or may not be delivered. The London Bullion Market Association (LBMA) provides governance for a physical market structure with reliable historical records dating back to 1660 (London Bullion Market Association, 2017). In 1671, Moses Mocatta founded a firm that would become the oldest member of the London bullion market (now known as the Bank of Scotia - ScotiaMocatta). Mocatta's firm began delivering gold to India via the East India Company in 1676. Undoubtedly, due to this prominence in precious metals trading, Mr. Mocatta's son (Abraham Mocatta) was appointed as the official gold and silver broker for the Bank of England in 1731. Fast-forward 140 years, Arnold (2016) notes that global trade was built around the gold standard from 1871 to 1914 whereby paper currencies had an underlying quantity of gold as their basis. National demand for gold was extensive during this timeframe as refiners in London were handling all of the newly mined South African gold. This activity allowed the city to become a prominent hub regarding precious metals trading. 
The current London physical market consists of trading in an over-the-counter (OTC) structure with trades cleared through a central electronic clearing hub managed by London Precious Metal Clearing Limited (LPMCL). The five members of the LPMCL are HSBC Bank plc, ICBC Standard Bank Plc, JPMorgan Chase Bank N.A. (London Branch), The Bank of Nova Scotia - ScotiaMocatta and UBS A.G. (London Branch) (London Precious Metals Clearing Limited, 2017). Loco London refers to the gold and silver bullion physically held in London by seven members of the LBMA, together with the Bank of England. In 2019, the total amount of gold cleared in the market was 242.80 million ounces at a value of $\$ 338.40$ billion and the amount of silver cleared was 3,044.90 million ounces at a value of $\$ 49.40$ billion (London Bullion Market Association, 2020a).

Arnold (2016) further describes the impetus for the first gold "fix" in 1919. Due to the outbreak of World War I, the gold standard was essentially (although not formally) suspended and Britain took actions in 1914 to safeguard and control gold output. The Bank of England was given authority to buy all the extensive quantities of gold produced in South Africa at an official rate. Also, the Bank was allowed to provide interest-free advances to the producers at $97 \%$ of the value of the gold. However, by the end of the war, the price of gold in New York was higher than in London and the Bank of England took protective measures to maintain London's status as the primary gold market. Intending to maintain the South African mining output, N.M. Rothschild \& Sons took over the market-making role to garner the best price possible for the mines. The Bank of England acted as a depository and all refiners delivered gold to Rothschild \& Sons, who then determined the best possible price by 11:00 each morning. The South African mines trusted Rothschild \& Sons as the firm set the daily price based on information gathered from the various exchanges, with brokers having the opportunity to bid. Thus, the first gold price "fix" took place on September 12, 1919. In addition to Rothschild \& Sons, four other brokers previously involved in the London silver fix since 1897 participated in the gold fix.

\section{Futures Market}

Gold and silver futures contracts trade according to the rules of the Commodity Exchange (COMEX). COMEX merged with the New York Mercantile Exchange (NYMEX) in 1994 and both exchanges joined the Chicago Mercantile Exchange Group (CME) in 2008. Trading of precious metals occurs in a trading ring on a combined energy and metals trading floor in New York (CME Group, 2017). The CME provides a Globex electronic trading platform that is open 23 hours per day. The futures contract information for these precious metals is available on the CME website. The silver and gold contracts used in this study are both deliverable with contract sizes of 5,000 troy ounces and 100 troy ounces, respectively.

The Globex futures contracts for both silver and gold open at 5:00 p.m. Central time and close the next day at 4:00 p.m. The London AM gold fix occurs at 4:30 a.m. Central (10:30 a.m. London) while the London PM gold fix occurs at 9:00 a.m. Central (3:00 p.m. London). The London silver fix occurs once per day at 6:00 a.m. Central (12:00 p.m. London).

Figure 1 depicts the gold pricing timeline. The closing price of the gold futures occurs seven hours after the London PM spot price. Likewise, the opening price of the gold futures contract is also delayed several hours after the London spot prices are available. The delay between the London fix price and the futures close and open is even greater in the silver market. These differences in timing have previously been studied to better understand information flow and price discovery across markets (e.g., Hauptfleisch et al., 2016 and Lucey et al., 2013).

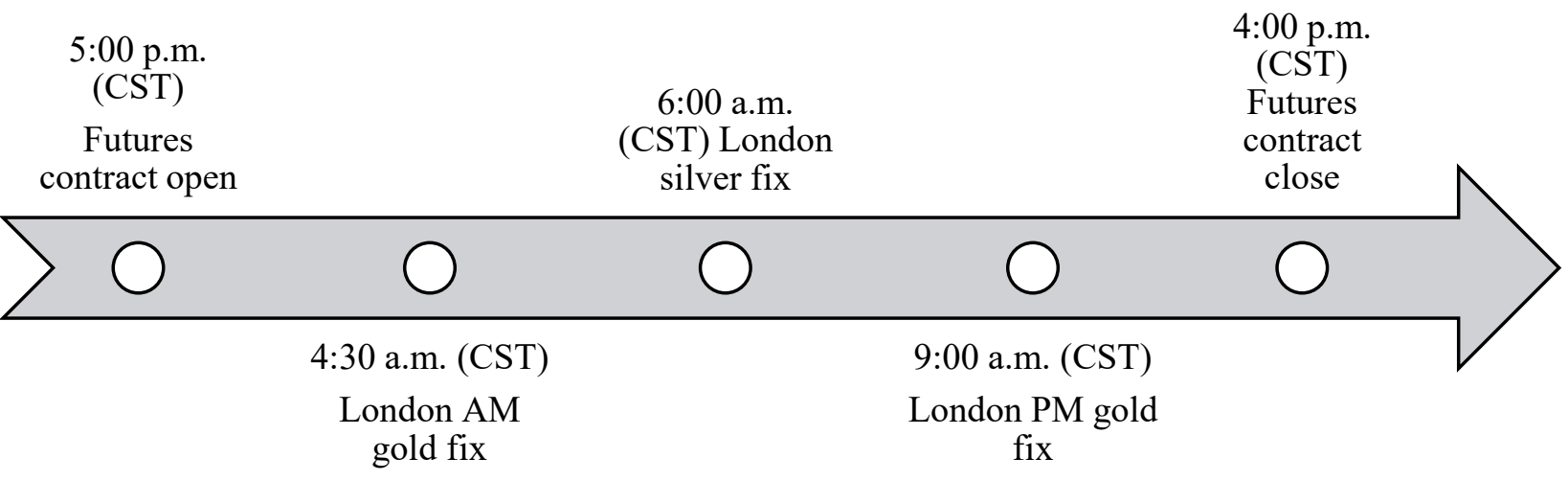

Figure 1. Timeline of Gold and Silver Pricing 
Data

Daily prices, open interest, and the trading volume for futures contracts on silver and gold trading on the Chicago Mercantile Exchange Globex platform are obtained from Commodity Systems Incorporated over the sample period of January 1, 2008, through June 27, 2018. A single series of prices is created in each market whereby the nearby contract is rolled to the next contract month when the volume of trading in the next month exceeds the nearby. This methodology ensures the most liquid contract is represented. The daily London fix prices are obtained from the LBMA website (www.lbma.org.uk). Implied volatility is obtained from Bloomberg for both gold (Bloomberg symbol: IVOLGOLD Index) and silver (Bloomberg symbol: IVOLSILV Index).

\section{Methodology and Results}

Preliminary analysis of returns was conducted with t-tests for differences between the pre-fix change period and the post-fix change period. No significant differences were evident. On the other hand, the volume of trading and open interest in the futures contracts increased significantly in the post-fix change period in both silver and gold markets. For brevity, the results are excluded here but the results are available from authors upon request. Since previous market manipulation literature has focused on volatilities, we now turn our attention to an extensive analysis of several measures of volatility.

\section{Volatility Analysis}

Beyond using the high minus low price as a preliminary measure of volatility, we also supplement it with three other volatility measures in this analysis. The first is a more sophisticated and efficient measure of volatility which was developed by Garman and Klass (1980) and utilizes open, high, low, and close data for each day as follows:

$$
\sigma_{24 h r}^{2}=0.5[u-d]^{2}-[2 \ln (2)-1] c^{2}
$$

where $\mathrm{u}=\ln ($ high $)-\ln$ (open), $\mathrm{d}=\ln ($ low $)-\ln$ (open) and $\mathrm{c}=\ln$ (close) $-\ln$ (open). This equation assumes that the markets are always open over a 24-hour period. For the case where the markets are closed for a fraction of the day (denoted $\mathrm{f}$ ) and the possibility of jumps in prices from close to open can occur, the adjusted measure becomes:

$$
\sigma_{<24 h r}^{2}=a \frac{\left(\ln \left(\text { open }_{t}\right)-\ln \left(\text { (lose }_{t-1}\right)\right)^{2}}{f}+(1-a) \frac{\widehat{\sigma}_{24 h r}^{2}}{(1-f)}
$$

where $\mathrm{a}=0.12$ provides the minimized variance of the measure. In the case of the silver and gold markets, trading does not occur for one hour of each day resulting in an $f$ value of $1 / 24$.

Our second measure is the daily 3 -month implied volatility computed at 100 percent moneyness and our third measure of volatility is estimated from a $\operatorname{GARCH}(1,1)$ model as follows:

$$
\begin{aligned}
& \ln \frac{\text { Price }_{t}}{\text { Price }_{t-1}}=\mu+\varepsilon_{t} \\
& \varepsilon_{t} \mid \Omega_{t} \sim t d\left(0, \sigma_{t}^{2}, v\right) \\
& \sigma_{t}^{2}=\omega+\alpha \varepsilon_{t-1}^{2}+\gamma \sigma_{t-1}^{2}+\theta_{t} d_{u m_{t}}
\end{aligned}
$$

where $\operatorname{td}(0 \sigma 2 \mathrm{t}, v)$ represents the student's $t$ density with mean zero, variance $\sigma 2 \mathrm{t}$ and degrees of freedom $v$. We include an indicator variable for the fix change period in the variance equation.

Silver Volatility

Table 1 provides the preliminary volatility analysis results over the full sample period of January 2, 2008, through June 27, 2018, for silver futures markets. In the silver futures market (Panel A of Table 1) the high price of the day 
minus the low price of the day is significantly lower in the post-fix change period indicating a reduction in volatility. The Kruskal-Wallis non-parametric tests reinforce the evidence from the t-tests. The next two columns provide the Garman-Klass volatility measures for futures using both a 24-hour calculation and a 23-hour calculation. In all instances, the standard deviations are significantly lower in the post-fix change period. The last column of Panel A reports the results of the analysis focusing on the implied volatility of silver, which also confirms statistically lower volatility following the change of the price fix structure.

Table 1. Volatility Analysis of Silver Markets

\begin{tabular}{|c|c|c|c|c|}
\hline \multicolumn{5}{|l|}{ Panel A: Tests for Differences } \\
\hline & \multirow{3}{*}{$\begin{array}{c}\text { Futures } \\
\mathrm{H}-\mathrm{L}\end{array}$} & \multicolumn{2}{|c|}{ Garman-Klass Standard Deviations } & \multirow{3}{*}{$\begin{array}{l}\text { Implied } \\
\text { Volatility }\end{array}$} \\
\hline & & & & \\
\hline & & 24 hour & 23 hour & \\
\hline $\begin{array}{c}1 / 2 / 2008-8 / 14 / 2014 \\
(N=1,638)\end{array}$ & 0.7739 & 0.000625 & 0.000763 & 35.1575 \\
\hline $\begin{array}{c}8 / 15 / 2014-6 / 27 / 2018 \\
(\mathrm{~N}=956)\end{array}$ & 0.3742 & 0.000253 & 0.000305 & 23.384 \\
\hline$t$-test & $25.99^{* * *}$ & $11.02^{* * *}$ & $10.69^{* * *}$ & $42.44^{* * *}$ \\
\hline Kruskal-Wallis & $766.19^{* * *}$ & $397.74^{* * *}$ & $345.94^{* * *}$ & $1155.32^{* * *}$ \\
\hline
\end{tabular}

$$
\sigma_{t}^{2}=\omega+\alpha \varepsilon_{t-1}^{2}+\gamma \sigma_{t-1}^{2}+\theta_{t} d u m_{t}
$$

\begin{tabular}{lccc}
\hline & Futures Open-to-Open & Futures Close-to-Close & London \\
\hline \multirow{2}{*}{$8.7699 \mathrm{E}-6^{* *}$} & $0.00001^{* *}$ & $\left(2.8094 \mathrm{E}-6^{* *}\right.$ \\
& $(2.80)$ & $(2.79)$ & $(3.04)$ \\
$\alpha$ & $0.0609^{* * *}$ & $0.0576^{* * *}$ & $0.0613^{* * *}$ \\
& $(5.46)$ & $(5.09)$ & $(6.02)$ \\
$\gamma$ & $0.9268^{* * *}$ & $0.9308^{* * *}$ & $0.9226^{* * *}$ \\
$\theta$ & $(71.48)$ & $(72.24)$ & $(74.64)$ \\
& $-4.471 \mathrm{E}-6^{*}$ & $-5.932 \mathrm{E}-6^{*}$ & $-5.672 \mathrm{E}-6^{*}$ \\
\hline
\end{tabular}

Panel C: GARCH $(1,1)$ Estimations Split into Pre- and Post-Fix Change Periods

$$
\sigma_{t}^{2}=\omega+\alpha \varepsilon_{t-1}^{2}+\gamma \sigma_{t-1}^{2}
$$

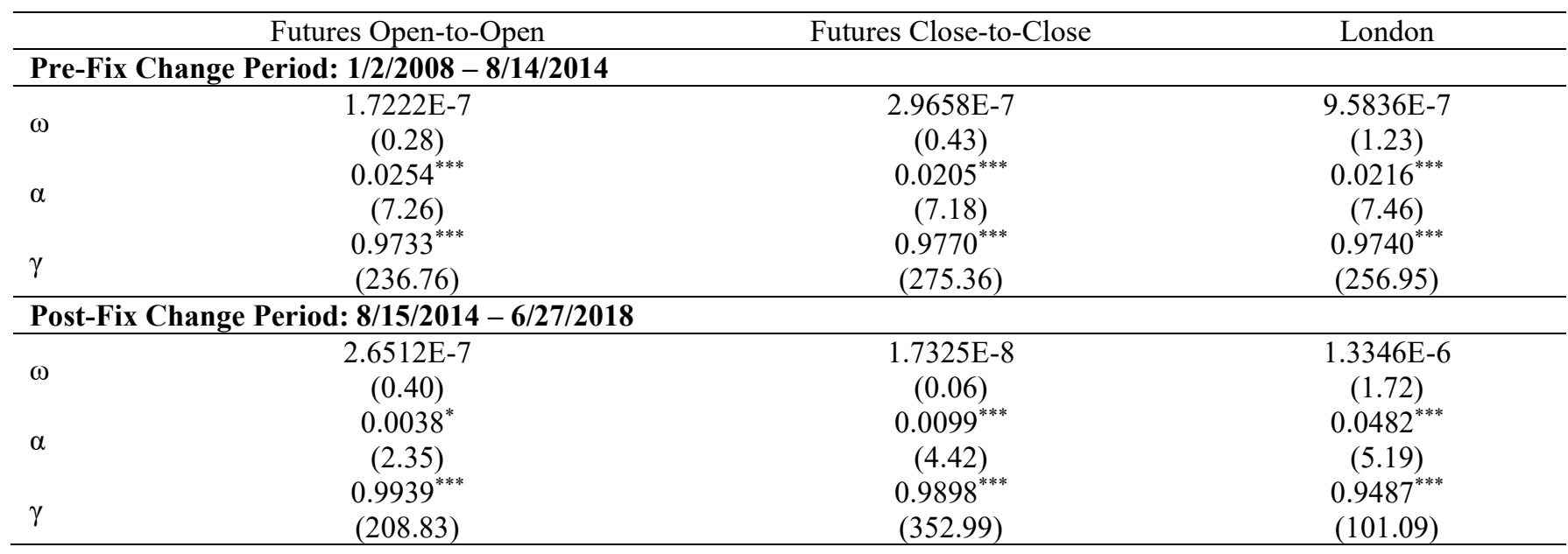


Panel D: Differences in Conditional Variance

\begin{tabular}{cccc}
\hline & Futures Open-to-Open & Futures Close-to-Close & London \\
\hline $1 / 2 / 2008-8 / 14 / 2014$ & 0.00055 & 0.00056 & 0.00060 \\
$8 / 15 / 2014-6 / 27 / 2018$ & 0.00018 & 0.00023 & 0.00023 \\
$t$-test & & & $35.21^{* * *}$ \\
Kruskal-Wallis & $36.65^{* * *}$ & $36.39^{* * *}$ & $1100.87^{* * *}$ \\
\hline
\end{tabular}

Note: $* * * \mathrm{p}<0.001, * * \mathrm{p}<0.01, * \mathrm{p}<0.05$

Turning to the GARCH $(1,1)$ estimations in Panel B covering the full sample period of January 2, 2008, through June 27, 2018, the coefficient of interest is the indicator variable $(\theta)$ for the fix-change period. Across all silver markets, the change indicator coefficients are all negative and significant at the 5 percent level. To provide supporting evidence for the significance of the indicator variable in Panel B, we divide the sample period into pre- and post-fix change periods and estimate the GARCH $(1,1)$ model for each sub-sample. Panel C provides these estimates. It was necessary to introduce an AR (1) term for the London spot price in the pre-fix change period to achieve white noise in the model. For each market and within each sub-period, we obtain the conditional variance from the fitted GARCH $(1,1)$ model and then test for differences between the pre-fix change and post-fix change periods. The results in Panel $\mathrm{D}$ unequivocally show lower conditional volatilities in the post-fix change period with corresponding significant $t$ test and Kruskal-Wallis non-parametric $p$-values at the 0.1 percent level $(p<0.001)$. Collectively, Table 1 provides strong evidence that volatility in the silver market substantially declined following the change to the price fix mechanism in the London spot market on August 15, 2014.

Gold Volatility

We now explore whether a similar impact to volatility is evident in the gold market. Table 2 provides evidence in favor of the same conclusions for gold markets as were found for silver markets. All volatility measures shown in Panel A are significantly lower in the post-fix change period with $p$-values less than 0.001 . The GARCH $(1,1)$ model estimates shown in Panel B also report negative estimates on the indicator variable $(\theta)$ for the fix-change period. The spot market is AR (1) to achieve white noise. All indicator variable coefficients are significant at either the 5 percent $(p<0.05)$ or 1 percent $(p<0.01)$ levels. Panel C provides the sub-sample period GARCH $(1,1)$ model estimates. The analysis of the conditional variances from the fitted model is in Panel D and provides evidence of significant reductions of volatility in the post-fix change period. 
Table 2. Volatility Analysis of Gold Markets

\section{Panel A: Tests for Differences}

\begin{tabular}{|c|c|c|c|c|}
\hline & \multicolumn{3}{|c|}{ Garman-Klass Standard Deviations } & \multirow{3}{*}{$\begin{array}{l}\text { Implied } \\
\text { Volatility }\end{array}$} \\
\hline & \multirow{2}{*}{$\begin{array}{c}\text { Futures } \\
\mathrm{H}-\mathrm{L}\end{array}$} & \multicolumn{2}{|c|}{ Futures } & \\
\hline & & 24 hour & 23 hour & \\
\hline $\begin{array}{l}1 / 2 / 2008-3 / 19 / 2015 \\
(\mathrm{~N}=1,770)\end{array}$ & 23.3889 & 0.000195 & 0.000246 & 21.0512 \\
\hline $\begin{array}{l}3 / 20 / 2015-6 / 27 / 2018 \\
(\mathrm{~N}=802)\end{array}$ & 15.6350 & 0.000078 & 0.000104 & 13.7126 \\
\hline$t$-test & $18.02^{* * *}$ & $12.44^{* * *}$ & $10.01^{* * *}$ & $39.20^{* * *}$ \\
\hline Kruskal-Wallis & $322.45^{* * *}$ & $307.90^{* * *}$ & $231.84^{* * *}$ & $993.48^{* * *}$ \\
\hline
\end{tabular}

Panel B: GARCH $(1,1)$ Estimations over Entire Sample

$$
\sigma_{t}^{2}=\omega+\alpha \varepsilon_{t-1}^{2}+\gamma \sigma_{t-1}^{2}+\theta_{t} d u m_{t}
$$

\begin{tabular}{|c|c|c|c|c|}
\hline & Futures Open-to-Open & Futures Close-to-Close & London AM & London PM \\
\hline \multirow{2}{*}{$\omega$} & $8.5625 \mathrm{E}-6^{* * *}$ & $9.0345 \mathrm{E}-6^{* * *}$ & $0.000018^{* *}$ & $0.000011^{* * *}$ \\
\hline & $(3.85)$ & $(3.57)$ & $(4.26)$ & $(3.80)$ \\
\hline \multirow[b]{2}{*}{$\alpha$} & $0.1300^{* * *}$ & $0.1087^{* * *}$ & $0.1899^{* * *}$ & $0.1226^{* * *}$ \\
\hline & $(5.39)$ & $(4.73)$ & $(5.64)$ & $(4.88)$ \\
\hline & $0.8256^{* * *}$ & $0.8458^{* * *}$ & $0.7497^{* * *}$ & $0.8209^{* * *}$ \\
\hline$\gamma$ & $(28.97)$ & $(28.95)$ & $(20.81)$ & $(26.03)$ \\
\hline$\theta$ & $-3.178 \mathrm{E}-6^{*}$ & $-3.649 \mathrm{E}-6^{*}$ & $-6.063 \mathrm{E}-6^{* *}$ & $-5.346 \mathrm{E}-6^{* *}$ \\
\hline$\theta$ & $(-2.28)$ & $(-2.44)$ & $(-2.86)$ & $(-2.88)$ \\
\hline
\end{tabular}

$$
\sigma_{t}^{2}=\omega+\alpha \varepsilon_{t-1}^{2}+\gamma \sigma_{t-1}^{2}
$$

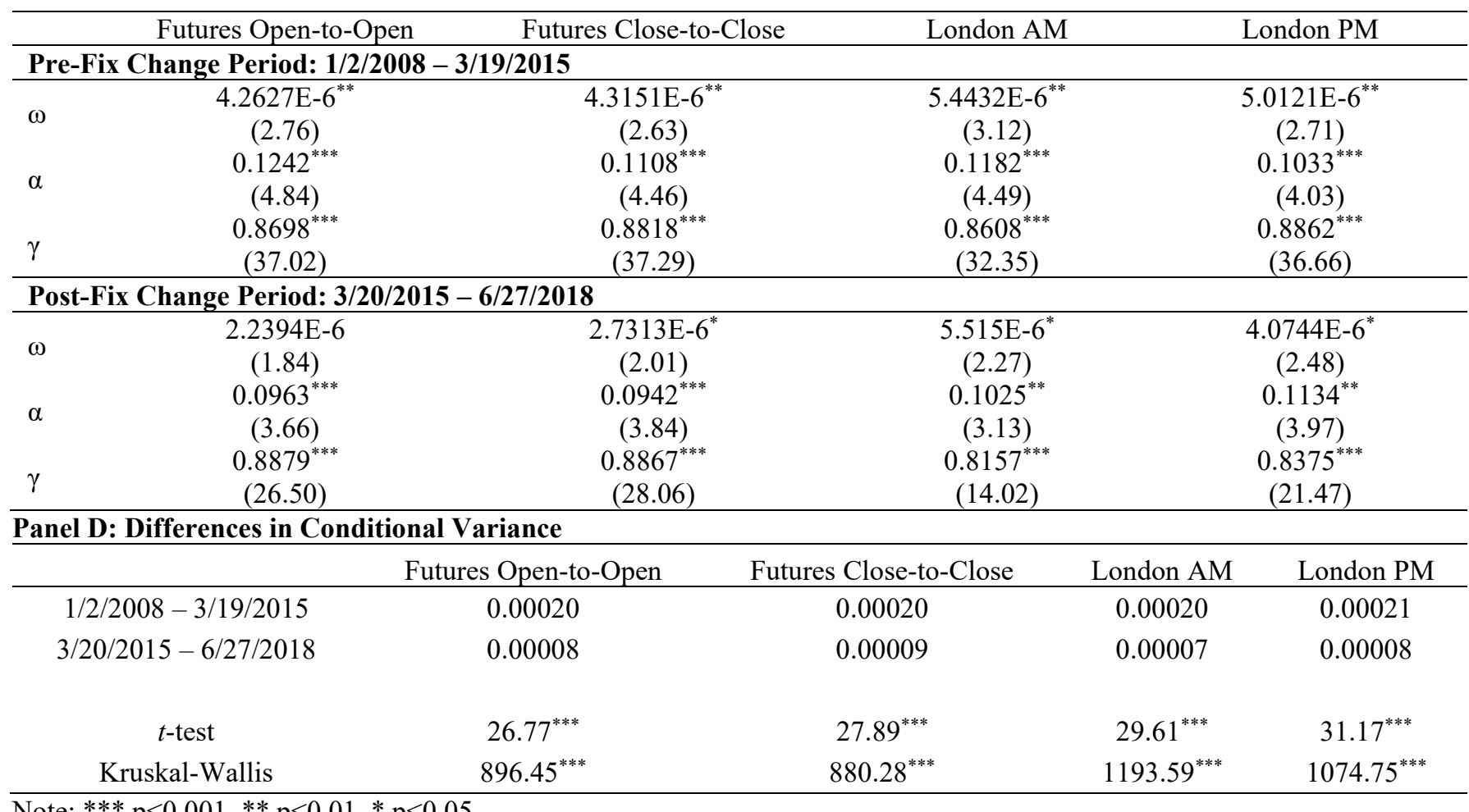

Note: $* * * \mathrm{p}<0.001,{ }^{*} \mathrm{p}<0.01, * \mathrm{p}<0.05$ 


\section{Summary}

The significantly lower volatilities in the futures market for both silver and gold following the changes to the price fix mechanisms provide initial support for Hypothesis 1 and rejection of Hypothesis 2. Based on the underlying premise of Kumar and Seppi (1992), it is possible that prior to the fix change, informed traders were placing derivatives positions based on their inside information for the upcoming daily fix in the London market. However, the Genesove and Mullin (2001) and Abrantes-Metz et al. (2006) models for coordination among informed price fix participants is not supported given the decreased volatilities.

\section{Spot Market and Futures Market Relationship}

In light of the volatility differences found in both the silver and gold markets with the changing of the price fixing mechanism as a possible reason, we now explore the relationship between the London spot market and the futures market. Figure 2 shows the conditional variances from the fitted GARCH $(1,1)$ models for each market from January 2,2008 , through June 27, 2018. The visual evidence suggests a high degree of similarity between the futures and the spot.
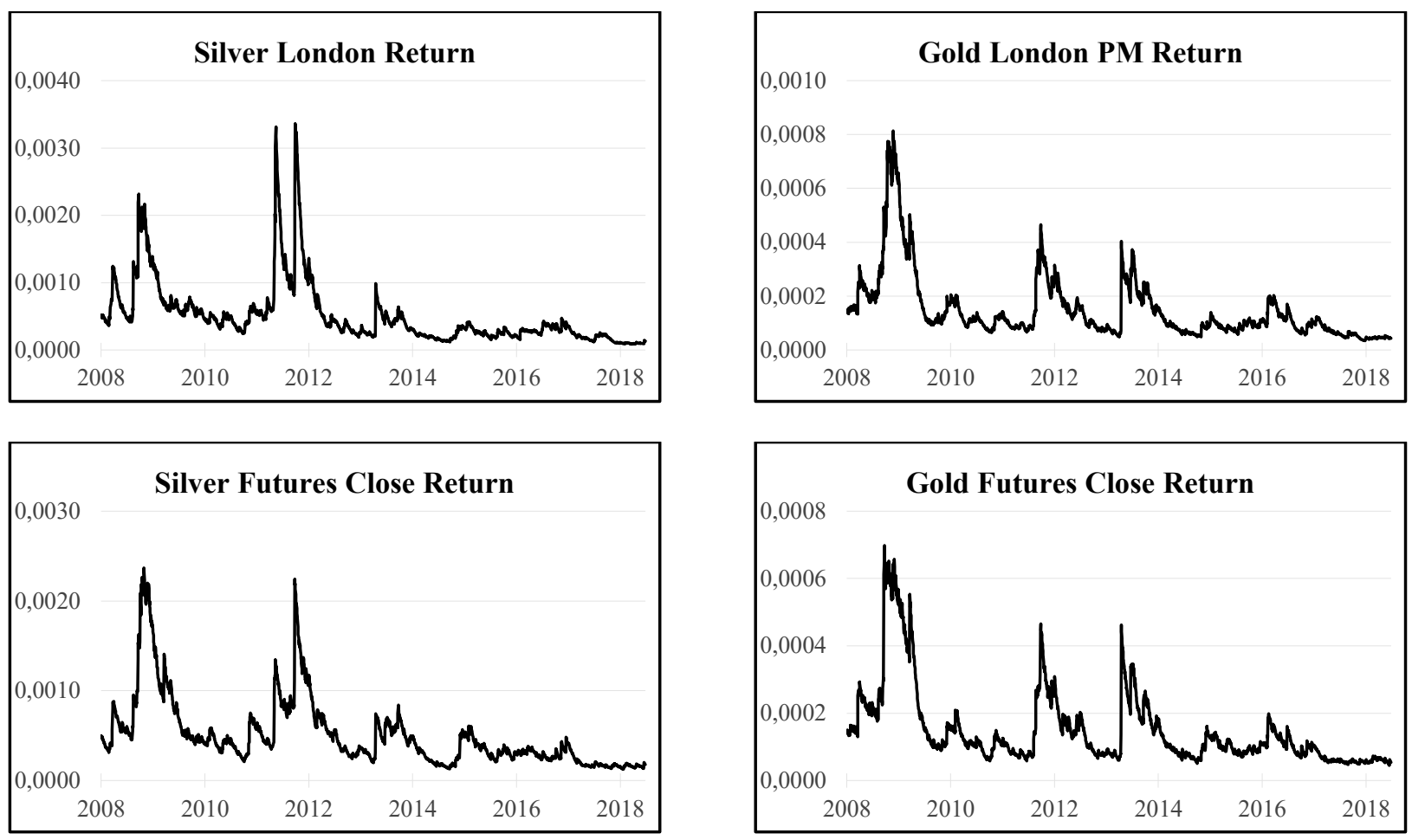

Figure 2. Estimated Conditional Error Variances for $\operatorname{GARCH}(1,1)$ Models

Silver Markets

To have a consistent volatility measure for both the London market and the futures market, we use the GARCH conditional error variances as open, high, and low prices are unavailable for the London spot market. Additional testing consists of regression analysis for the impact of London volatility on futures volatility as follows:

$$
\begin{aligned}
& \text { Silver Futures } C E V_{t}=\alpha+\beta_{1}{\text { London } C E V_{t}+\beta_{2} \text { Silver Fix Change Indicator }}^{+\beta_{3} \text { Gold Futures } C E V+\beta_{4} \text { Gold Futures CEV x Silver Fix Change Indicator }+\varepsilon}
\end{aligned}
$$

In this instance, we only use the close-to-close returns for the futures contracts. The Silver Fix Change Indicator variable equals 1 for the dates post-change and equals 0 for the dates pre-change. The conditional error variance (CEV) from the GARCH $(1,1)$ model in the London spot market is an explanatory variable. We include the gold futures conditional variance as an independent variable to control for other general conditions in the metals market. Panel A of Table 3 reports the results for the silver market. 
Model 1 only includes the London variance and the silver fix change indicator. As one might expect, the volatility of the London market positively impacts futures volatility. However, the indicator variable for the price fix change is negative and highly significant suggesting a reduction in futures volatility since the fix change. Likewise, when we include the gold futures volatility in Model 2, the fix change indicator remains significantly negative. The volatility in the gold futures spills over into the silver market and seems to play an even bigger role than the London silver volatility. In fact, the London silver spot volatility has a lower coefficient than in Model 1. In the last column, Model 3 includes an additional interaction term between gold futures volatility and the Silver Fix Change Indicator. This interaction variable examines the impact of gold volatility on silver after the fix change was made in the silver market. The insignificance of the coefficient shows that the contribution of gold futures volatility to silver futures volatility did not change following the silver fix change. The addition of the interaction variable does not influence the sign of the silver fix change indicator or the explanatory power of the model.

Table 3. GARCH Conditional Error Variance Analysis of Silver Markets

\begin{tabular}{|c|c|c|c|c|}
\hline \multicolumn{5}{|c|}{ Panel A: Silver Futures Close-to-Close Return Regressions } \\
\hline & & $(1)$ & (2) & (3) \\
\hline London CEV & & $0.64475^{* * *}$ & $0.47171^{* * *}$ & $0.47181^{* * *}$ \\
\hline Silver Fix Change Indicator & & $-0.00011^{* * *}$ & $-0.00006^{* * *}$ & $-0.00006^{* *}$ \\
\hline Gold Futures CEV & & & $1.34162^{* * *}$ & $1.34007^{* * *}$ \\
\hline Gold Futures CEV * Silver Fix Change Indicator & & & & 0.03174 \\
\hline Adj. $R^{2}$ & & 0.7569 & 0.8644 & 0.8644 \\
\hline Number of observations & & 2,571 & 2,571 & 2,571 \\
\hline \multicolumn{5}{|c|}{$\begin{array}{l}\text { Panel B: Difference-in-Difference Futures Close-to-Close Return Regressions } \\
\end{array}$} \\
\hline & $(1)$ & (2) & (3) & (4) \\
\hline & $1 / 2 / 2008$ & $8-6 / 27 / 2018$ & $1 / 15 / 201$ & $3 / 15 / 2015$ \\
\hline London CEV & & $0.65979^{* * *}$ & & $1.33152^{* * *}$ \\
\hline Silver Fix Change Indicator & $-0.00010^{* * *}$ & $-0.00003^{* * *}$ & $0.00002^{* * *}$ & 0.00001 \\
\hline Silver Indicator & $0.00046^{* * *}$ & $0.00015^{* * *}$ & $0.00019^{* * *}$ & -0.00000 \\
\hline Silver Indicator * Silver Fix Change Indicator & $-0.00030^{* * *}$ & $-0.00008^{* * *}$ & $0.00005^{* *}$ & $0.00003^{* *}$ \\
\hline Adj. $R^{2}$ & 0.4177 & 0.8199 & 0.5773 & 0.8051 \\
\hline Number of observations & 5,164 & 5,164 & 574 & 574 \\
\hline
\end{tabular}

Note: $* * * \mathrm{p}<0.001, * * \mathrm{p}<0.01,{ }^{*} \mathrm{p}<0.05$

The evidence to this point strongly supports a reduction in volatilities in the post-fix change period for silver (support for Hypothesis 1). However, an argument could be made that there is a general trend of reduced volatilities throughout time and that is what the preceding empirical procedures capture. Figure 2 provides visual and would provide empirical support for this argument. To explore this potential issue and provide assurance that the fix change itself is the reason, we construct a difference-in-difference model in Panel B of Table 3 as follows:

$$
\begin{aligned}
& \text { Futures } C E V_{i, t}=\alpha+\beta_{1} \text { London } C E V_{i, t}+\beta_{2} \text { Silver Fix Change Indicator } \\
& \quad+\beta_{3} \text { Silver Indicator }+\beta_{4} \text { Silver Indicator } x \text { Silver Fix Change Indicator }+\varepsilon
\end{aligned}
$$

When testing the silver futures market, the gold futures conditional variance is used for the control group to discern general trends in the metals market. In addition to the Silver Fix Change Indicator, we include an indicator variable to designate those observations from the silver market, Silver Indicator. This variable takes the value of one if the data reflects the silver market and zero if the data reflects the gold market. Model 1 does not include a control variable for the London spot market whereas Model 2 does. In both cases, the variable of interest is the interaction term since it will provide a measure of the actual impact of the silver fix change on the silver futures market. The results suggest that the London market volatility has a significant impact on the futures market volatility. The Silver Fix Change Indicator shows that volatilities are lower in the period following the change (August 15,2014) to the silver market. 
The Silver Indicator suggests that volatility in the silver market is generally higher than in the gold market. Finally, over the entire sample period, the interaction term is significantly negative indicating that the silver fix change has reduced volatility in the futures market controlling for a time trend relative to a control sample (i.e., gold futures market volatility). Once again, these results provide support for the Kumar and Seppi (1992) model which underlies Hypothesis 1.

A potential issue that needs addressing is the fact that the London gold fix itself was changed a mere seven months following the silver fix change. This overlap may result in a confounding effect over the longer-term sample period result. Therefore, a shortened sample period is constructed for the difference-in-difference model that ends immediately preceding the change to the gold fix procedure with a sample period that includes seven months prior and seven months after the silver fix change (1/15/2014 - 3/15/2015). In Model 3, the fix change indicator is significantly positive and the interaction term is positive and significant as well. After correcting for the London spot market in Model 4, both terms remain positive but the indicator term becomes insignificant and the size of the interaction term is reduced while remaining significant.

The conclusion from both Models 3 and 4 is that volatility appears to have significantly increased during this shortened sample period following the silver price fix change. In looking at the differences between the full sample and the shortened sample period, one can draw one of two conclusions. The first would be that following the gold fix change the volatility in the gold futures markets also increased (i.e., confounding effect) resulting in a significantly negative estimate over the full sample period. The alternative (or second conclusion) would be that the silver market had a short-term adjustment period that has reversed over the long run from 2015 to 2018. If the first explanation is correct, the increased volatility in the short run provides support for Hypothesis 2. The second explanation of the reversal of the short-term increased volatility trend over the subsequent period from 2015 to 2018 would support Hypothesis 1.

\section{Gold Markets}

We use the same analysis techniques from Table 3 for the silver futures market in Table 4 for the gold futures market. The two regression models are as follows:

$$
\begin{aligned}
& \text { Gold Futures } C E V_{t}=\alpha+\beta_{1} \text { London PM CEV }+\beta_{2} \text { Gold Fix Change Indicator } \\
& +\beta_{3} \text { Silver Futures CEV }+\beta_{4} \text { Silver Futures CEV } x \text { Gold Fix Change Indicator }+\varepsilon \\
& \text { Futures CEV } V_{i, t}=\alpha+\beta_{1} \text { London PM CEV } V_{i, t}+\beta_{2} \text { Gold Fix Change Indicator } \\
& +\beta_{3} \text { Gold Indicator }+\beta_{4} \text { Gold Indicator } x \text { Gold Fix Change Indicator }+\varepsilon
\end{aligned}
$$

Starting with Panel A, we see that the London PM spot volatility is highly significant in determining volatility in the gold futures market. In contrast to the silver market, the gold fix change indicator is only significantly negative in Model 1. Although the silver futures volatility spills over to the gold futures, the effect is much smaller than the spillover from gold to silver. The interaction between silver futures volatility and the Gold Fix Change Indicator is also insignificant. It appears that the gold fix change in London was not as significant an event as the silver fix change, which is understandable as the silver market had already changed the fixing process prior to the gold fix change. 
Table 4. GARCH Conditional Error Variance Analysis of Gold Markets

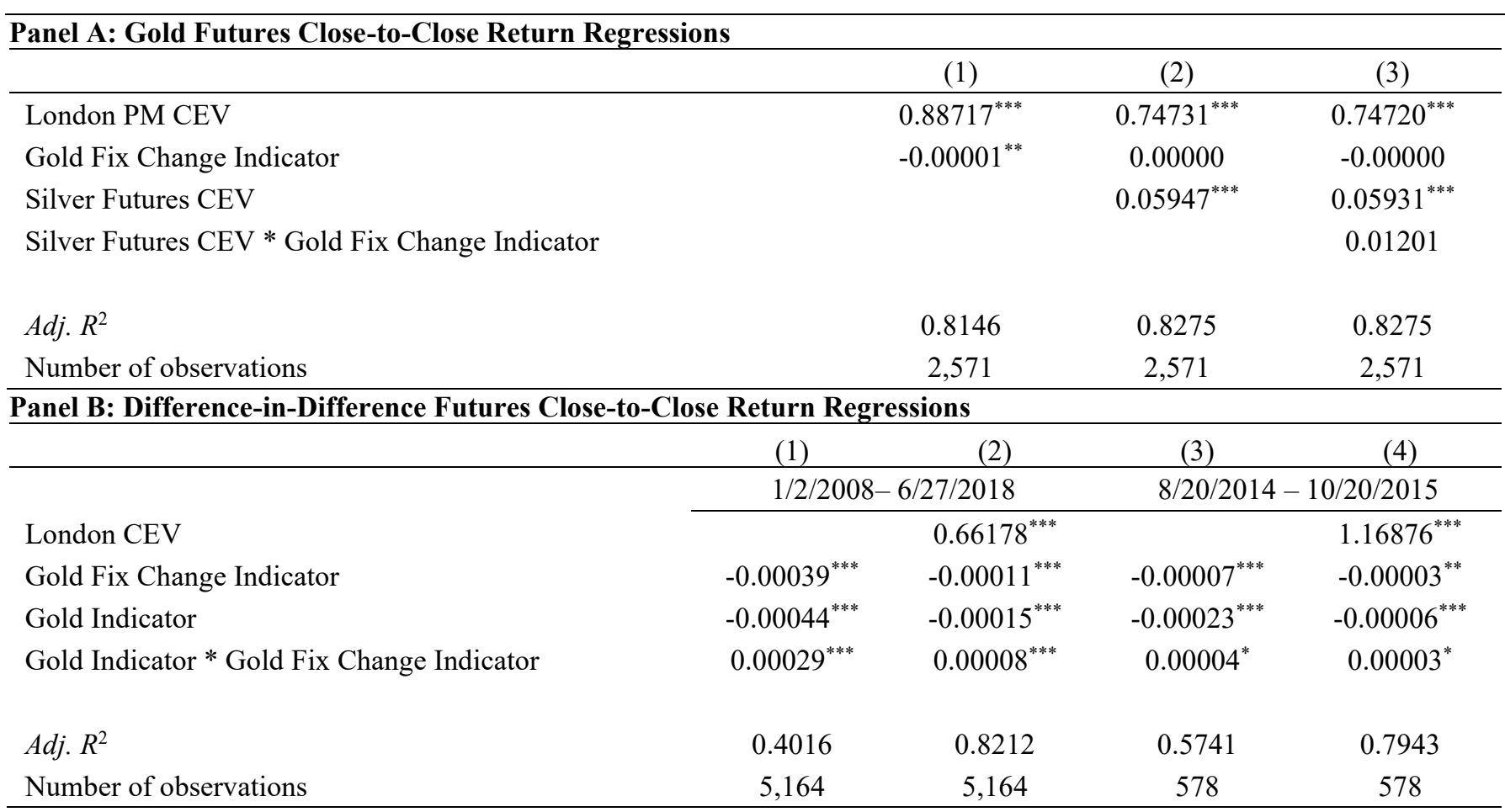

Note: $* * * \mathrm{p}<0.001, * * \mathrm{p}<0.01, * \mathrm{p}<0.05$

Turning to Panel B using the difference-in-difference methodology, the silver futures conditional variance is used as the control group. As expected, the London PM volatility in Model 2 is significant in explaining the volatility in the futures market and gold volatilities are lower than silver volatilities. Interestingly, the interaction term is positive and highly significant in both Models 1 and 2, which is the opposite result of the silver market for the full sample period. Thus, the gold fix change led to an increase in volatility in gold futures following the change to the gold fixing process. As mentioned previously, the fix change in silver and gold were only seven months apart. Once again we use a shortened sample period of seven months prior to the gold fix change (March 20,2015) to seven months after the gold fix change (8/20/2014 - 10/20/2015) to eliminate the potential for the confounding effect. In Models 3 and 4 , the interaction terms remain significantly positive, similar to the full sample period, but with lower coefficient estimates.

The evidence from Panel B suggests that volatilities increased following the gold fix change regardless of the sample period after controlling for the time trend relative to the control sample (i.e., silver futures market). This finding supports Hypothesis 2. The results from Table 4 suggest that the increased volatility in the gold market (i.e., confounding effect) likely contributes to the significantly lower volatility evidence in the silver market (Table 3 ) over the entire period. Collectively, when examining a clean sample period, the silver market experienced significantly higher volatility following the silver fix change similar to the evidence from the gold market after controlling for a time trend relative to a comparable sample supporting the confounding explanation and Hypothesis 2.

\section{Robustness Analysis}

Although we find strong evidence of changes in volatilities in the gold and silver markets following the change in the fixing procedure in the London spot market, we conduct further robustness tests to solidify the results. The West Texas Intermediate (WTI) sweet crude oil futures contract that trades at the New York Mercantile Exchange (NYMEX) is chosen for comparison purposes (i.e., control sample) as WTI represents the commodity with the highest level of futures trading (CME Group, 2018) and experiences no change in how prices are determined over our sample period. We replicate the analysis for gold and silver volatility from Tables 1, 2, 3, and 4 using the crude oil futures contract and report the findings in Table 5.

In Panel A, the GARCH $(1,1)$ model is fit for WTI futures over the entire sample period with an indicator variable for the fix change and then refit over the sub-periods before and after the silver and gold price fix date changes, 
respectively. As the fix change occurred on two different dates for silver and gold, the first three columns contain estimates for crude oil futures relative to the silver price fix change date and the last three columns contain estimates for crude futures relative to the gold price fix change date. The variable of interest is the indicator variable $(\theta)$ for the fix change period in Models 1 and 4 where we see an insignificant positive coefficient in both markets. This finding contrasts to the silver and gold futures evidence where the values were significantly negative. The lack of statistical significance lends further credence to the notion that the change in price fixing as being the driver for the differences in the silver and gold markets, respectively, and we are not just documenting a time trend in the futures market where volatility has decreased over time.

Table 5. Robustness Analysis Using Crude Oil Futures

\begin{tabular}{|c|c|c|c|c|c|c|}
\hline \multicolumn{7}{|c|}{$\begin{array}{l}\text { Panel A: GARCH (1, 1) Estimations over Various Sample Periods } \\
\qquad \sigma_{t}^{2}=\omega+\alpha \varepsilon_{t-1}^{2}+\gamma \sigma_{t-1}^{2}+\theta_{t} d u m_{t}\end{array}$} \\
\hline & (1) & (2) & (3) & (4) & (5) & (6) \\
\hline & $\begin{array}{c}\text { Silver } \\
\text { Full Period } \\
1 / 2 / 2008- \\
6 / 27 / 2018 \\
\end{array}$ & $\begin{array}{c}\text { Silver } \\
\text { Pre-Fix } \\
\text { Change } \\
\text { 1/2/2008- } \\
8 / 14 / 2014 \\
\end{array}$ & $\begin{array}{c}\text { Silver } \\
\text { Post-Fix } \\
\text { Change } \\
8 / 15 / 2014- \\
\text { 6/27/2018 } \\
\end{array}$ & $\begin{array}{c}\text { Gold } \\
\text { Full Period } \\
1 / 2 / 2008- \\
6 / 27 / 2018 \\
\end{array}$ & $\begin{array}{c}\text { Gold } \\
\text { Pre-Fix } \\
\text { Change } \\
\text { 1/2/2008- } \\
3 / 19 / 2015 \\
\end{array}$ & $\begin{array}{c}\text { Gold } \\
\text { Post-Fix } \\
\text { Change } \\
3 / 20 / 2015- \\
\text { 6/27/2018 } \\
\end{array}$ \\
\hline$\omega$ & $\begin{array}{c}3.6688 \mathrm{E}-6^{* *} \\
(2.63)\end{array}$ & $\begin{array}{c}3.0909 \mathrm{E}-6^{*} \\
(2.10)\end{array}$ & $\begin{array}{c}1.2897 \mathrm{E}-7 \\
(0.20)\end{array}$ & $\begin{array}{c}3.5851 \mathrm{E}-6^{* *} \\
(2.61)\end{array}$ & $\begin{array}{c}2.0484 \mathrm{E}-6 \\
(1.71)\end{array}$ & $\begin{array}{c}4.9462 \mathrm{E}-8 \\
(0.09)\end{array}$ \\
\hline$\alpha$ & $\begin{array}{c}0.0864^{* * *} \\
(6.55)\end{array}$ & $\begin{array}{c}0.0872^{* * *} \\
(5.29)\end{array}$ & $\begin{array}{c}0.0149^{* * *} \\
(4.64)\end{array}$ & $\begin{array}{c}0.0844^{* * *} \\
(6.54)\end{array}$ & $\begin{array}{c}0.0802^{* * *} \\
(5.37)\end{array}$ & $\begin{array}{c}0.0131^{* * *} \\
(4.62)\end{array}$ \\
\hline$\gamma$ & $\begin{array}{c}0.9072^{* * *} \\
(67.20)\end{array}$ & $\begin{array}{c}0.9088^{* * *} \\
(55.63)\end{array}$ & $\begin{array}{c}0.9840^{* * *} \\
(275.82)\end{array}$ & $\begin{array}{c}0.9104^{* * *} \\
(69.37)\end{array}$ & $\begin{array}{c}0.9215^{* * *} \\
(66.05)\end{array}$ & $\begin{array}{l}0.9861^{* * *} \\
(311.02)\end{array}$ \\
\hline$\theta$ & $\begin{array}{c}3.0581 \mathrm{E}-6 \\
(1.50)\end{array}$ & & & $\begin{array}{c}1.7621 \mathrm{E}-6 \\
(0.90)\end{array}$ & & \\
\hline
\end{tabular}

Panel B: Differences in Conditional Variance

\begin{tabular}{cccc}
\multicolumn{2}{c}{ Silver Fix Change } & \multicolumn{2}{c}{ Gold Fix Change } \\
Dates & Crude Futures & Dates & Crude Futures \\
\hline $1 / 2 / 2008-8 / 14 / 2014$ & 0.00056 & $1 / 2 / 2008-3 / 19 / 2015$ & 0.00060 \\
$8 / 15 / 2014-6 / 27 / 2018$ & 0.00059 & $3 / 20 / 2015-6 / 27 / 2018$ & 0.00055 \\
& & & \\
$t$-test & -1.20 & $t$-test & $2.18^{*}$ \\
Kruskal-Wallis & $228.3073^{* * *}$ & Kruskal-Wallis & $111.2219^{* * *}$ \\
\hline
\end{tabular}

Panel C: Crude Oil Futures Close-to-Close Return Regressions with Silver Fix Indicator

Crude Oil Futures $C E V_{t}=\alpha+\beta_{1}$ London $C E V_{t}+\beta_{2}$ Silver Fix Change Indicator $+\beta_{3}$ Gold Futures CEV + $\beta_{4}$ Gold Futures CEV x Silver Fix Change Indicator $+\varepsilon$

\begin{tabular}{lccc}
\hline & $(1)$ & $(2)$ & $(3)$ \\
\hline London CEV & $0.44765^{* * *}$ & $0.10916^{* *}$ & $0.12196^{* * *}$ \\
Silver Fix Change Indicator & $0.00027^{* * *}$ & $0.00037^{* * *}$ & -0.0000 \\
Gold Futures CEV & & $2.62436^{* * *}$ & $2.41465^{* * *}$ \\
Gold CEV * Silver Fix Change Indicator & & & $4.28131^{* * *}$ \\
& & & \\
Adj. $R^{2}$ & 0.1074 & 0.2753 & 0.2999 \\
Number of observations & 2,571 & 2,571 & 2,571 \\
\hline
\end{tabular}


Panel D: Crude Oil Futures Close-to-Close Return Regressions with Gold Fix Indicator

Crude Oil Futures $C E V_{t}=\alpha+\beta_{1}$ London CEV $+\beta_{2}$ Gold Fix Change Indicator

$+\beta_{3}$ Silver Futures CEV $+\beta_{4}$ Silver Futures CEV $x$ Gold Fix Change Indicator $+\varepsilon$

\begin{tabular}{lccc}
\hline & $(1)$ & $(2)$ & $(3)$ \\
\hline London CEV & $2.74630^{* * *}$ & $1.44537^{* * *}$ & $1.42499^{* * *}$ \\
Gold Fix Change Indicator & $0.00031^{* * *}$ & $0.00040^{* * *}$ & $-0.00012^{*}$ \\
Silver Futures CEV & & $0.55321^{* * *}$ & $0.52327^{* * *}$ \\
Silver CEV * Gold Fix Change Indicator & & & $2.12477^{* * *}$ \\
& & & \\
Adj. $R^{2}$ & 0.2522 & 0.2953 & 0.3188 \\
Number of observations & 2,571 & 2,571 & 2,571 \\
\hline
\end{tabular}

Panel E: Difference-in-Difference Futures Close-to-Close Return Regressions for Silver and Crude

Futures $C E V_{i, t}=\alpha+\beta_{1}$ London $C E V_{i, t}+\beta_{2}$ Silver Fix Change Indicator

$+\beta_{3}$ Silver Indicator $+\beta_{4}$ Silver Indicator $x$ Silver Fix Change Indicator $+\varepsilon$

\begin{tabular}{|c|c|c|c|c|}
\hline & $(1)$ & $(2)$ & $(3)$ & $(4)$ \\
\hline & \multicolumn{2}{|c|}{$1 / 2 / 2008-6 / 27 / 2018$} & \multicolumn{2}{|c|}{$1 / 15 / 2014-3 / 15 / 2015$} \\
\hline London CEV & & $0.47694^{* * *}$ & & $3.09728^{* * *}$ \\
\hline Silver Fix Change Indicator & $-0.00010^{* * *}$ & $-0.00005^{* * *}$ & $0.00002^{* * *}$ & -0.00001 \\
\hline Silver Indicator & $0.00036^{* * *}$ & $0.00014^{* * *}$ & $0.00001^{* * *}$ & $-0.00043^{* * *}$ \\
\hline Silver Indicator * Silver Fix Change Indicator & $0.00017^{* * *}$ & $0.00033^{* * *}$ & $0.00060^{* * *}$ & $0.00056^{* * *}$ \\
\hline Adj. $R^{2}$ & 0.1838 & 0.2832 & 0.4996 & 0.6747 \\
\hline Number of observations & 5,164 & 5,164 & 574 & 574 \\
\hline
\end{tabular}

Futures $C E V_{i, t}=\alpha+\beta_{1}$ London $C E V_{i, t}+\beta_{2}$ Gold Fix Change Indicator

$+\beta_{3}$ Gold Indicator $+\beta_{4}$ Gold Indicator $x$ Gold Fix Change Indicator $+\varepsilon$

\begin{tabular}{lcccc}
\hline & $(1)$ & $(2)$ & $(3)$ & $(4)$ \\
\hline & $1 / 2 / 2008-6 / 27 / 2018$ & $8 / 20 / 2014-10 / 20 / 2015$ \\
\cline { 2 - 5 } London CEV & & $0.76910^{* * *}$ & & $1.50715^{* * *}$ \\
Gold Fix Change Indicator & $-0.00039^{* * *}$ & $-0.00007^{* * *}$ & $-0.00007^{* * *}$ & -0.00001 \\
Gold Indicator & $-0.00006^{* *}$ & $0.00028^{* * *}$ & $0.00039^{* * *}$ & $0.00061^{* * *}$ \\
Gold Indicator * Gold Fix Change Indicator & $0.00043^{* * *}$ & $0.00018^{* * *}$ & $0.00016^{* *}$ & $0.00014^{*}$ \\
& & & & \\
Adj. $R^{2}$ & 0.0629 & 0.3045 & 0.3030 & 0.3449 \\
Number of observations & 5,164 & 5,164 & 578 & 578 \\
\hline
\end{tabular}

Note:

$* * * \mathrm{p}<0.001, * * \mathrm{p}<0.01, * \mathrm{p}<0.05$

We replicate the volatility regressions from Tables 3 and 4 using crude oil futures and the results are in Panel C for silver and Panel D for gold, respectively. In the case of silver futures markets using silver futures close-to-close conditional variances as the dependent variable, the Silver Fix Change Indicator was significantly negative across all three models in Table 3, whereas the crude oil results in Panel $\mathrm{C}$ of Table 5 is significantly positive in Models 1 and 2 and becomes insignificant in Model 3. In the gold market analysis (i.e., Panel A of Table 4), the fix change indicator estimates using gold futures do not resemble the estimates shown for the crude oil futures (Panel D of Table 5). 
The final robustness test focuses on the difference-in-difference regressions used previously for silver futures and gold futures, respectively. The replicated regressions using crude oil futures as the control sample are reported in Panel E for silver and Panel F for gold, respectively. WTI serves as a valid control sample for both silver and gold as there was no change to how crude oil prices are determined during the sample period. The interaction term over the full sample period was previously shown to be significantly negative for silver and significantly positive for gold. Using the crude oil futures as the control group, the interaction term is significantly positive in all models for both the silver fix change and the gold fix change, respectively. The results in Panels E and F confirm the previous evidence and provide further support that after controlling for the time trend by using a control sample that both gold and silver markets experienced significantly greater volatility following the changes to the price fixing process. Collectively, the evidence in Table 5 supports Hypothesis 2.

\section{Price Cluster Analysis}

Our final test of differences between the pre- and post-fix change periods moves away from volatilities and concentrates on actual prices in the two markets (i.e., Hypothesis 3) with particular attention to Benford's Law as suggested by Abrantes-Metz et al. (2011). Using prices, we analyze the specific digits of the price to detect evidence of clustering. In the silver market, only the first digit to the right of the decimal is analyzed but in the gold market, both the first digit to the right of the decimal and the first digit to the left of the decimal are analyzed as gold prices are several times larger than silver prices over the sample period. The range of prices for the silver futures open is $\$ 8.96$ to $\$ 48.49$, for the silver futures close are $\$ 8.79$ to $\$ 48.60$, and the London spot is $\$ 8.88$ to $\$ 48.70$. The range of prices for the gold futures open is $\$ 708.40$ to $\$ 1,900.20$, for the gold futures close is $\$ 705.00$ to $\$ 1,891.90$, for the London AM spot is $\$ 692.50$ to $\$ 1,896.50$, and for the London PM spot is $\$ 712.50$ to $\$ 1,895.00$.

Table 6 presents the results from the price clustering analysis. For each of the digits that are possible, the table contains the percentage of observations in each digit class before and after the fix change. One argument is that each digit should be equally likely to occur in the price and this hypothesis can be tested using a Chi-square statistic. A second argument suggests that Benford's Law would apply whereby each successive digit from 0 to 9 will be represented by a lower proportion of actual outcomes with the distribution converging to uniform as the digit position moves to the right. Mathematically, the probability of the $n^{\text {th }}$ digit following the first non-zero digit (left to right scan) being equal to $d$ is:

$$
P_{n}\{d\}=\frac{1}{\ln (B)} \sum_{k=B^{n-1}}^{B^{n}-1} \ln \left(1+\frac{1}{k B+d}\right)
$$

where $\mathrm{d}=0,1,2, \ldots, 9$ and $\mathrm{B}$ is the base of the number system (base 10). Because of the left to right scanning in Benford's Law, the dollar digit is treated differently $(\mathrm{n}=1)$ for a two-integer digit price in the $\$ 10-\$ 99$ range compared to a four-integer digit price of $\$ 1000$ and above $(n=3)$. The right-most column of Table 6 shows the calculated Benford distribution for the $\$ 10-\$ 99$ price range for silver and the price range of $\$ 1000+$ for gold, respectively.

\section{Silver Markets}

Panel A (silver market prices) reports the percentage of time that each number is represented in the first digit to the right of the decimal for the futures open, futures close, and London PM price. The Chi-square statistic for equal distribution across the numbers is shown to be insignificant across all periods (pre- and post-fix change) and for all markets of silver prices. However, our Hypothesis 3 mirrors that of Abrantes-Metz et al. (2011) whereby a Benford distribution would be more applicable. When comparing silver spot prices to the Benford distribution shown in the last column, it appears that the spot prices are trending in that direction in the post-fix change period, whereas the same observation cannot be made in the futures market. As such, Hypothesis 3 for potential price manipulation prior to the fix change is supported for the London spot market but is not supported for the futures market.

\section{Gold Markets}

Panel B contains an analysis of the first digit to the left of the decimal for gold market prices. The futures prices are uniformly distributed in both sub-periods for both open and close futures prices. However, the spot markets exhibit 
non-uniformity in the pre-fix change periods with a change to uniformity in the post-fix change period. According to the Chi-square analysis, it appears that the auction market instituted by the fix change has altered price formation. None of the markets in either sub-period appears to follow Benford's Law for the first digit to the left of the decimal for gold prices. However, one could make an argument that the London PM price is trending toward the Benford distribution in the post-fix change period.

In Panel C, the first digit to the right of the decimal is analyzed for gold prices and reveals an unexpected outcome in the spot markets. Several of the digits were never quoted in the pre-fix change period. A logical explanation is that prices prior to the change in the price fixing mechanism primarily traded in increments of 0.25 resulting in high proportions for $0,2,5$, and 7 . The highly significant Chi-square values confirm that spot prices still do not satisfy a uniform distribution following the change to the gold price fix, however, all digits are now represented. Turning to the futures, the close prices are uniformly distributed only in the post-fix change period, whereas the futures open prices are non-uniform in both periods. Due to the gold price primarily trading in the $\$ 1,000+$ range, Benford's Law suggests a virtually uniform distribution for the cent digit. The overall results show a significant reduction in the ChiSquare statistics in the post-fix change period and a general trend approaching the Benford distribution. This suggests some evidence in support of Hypothesis 3.

Table 6. Cluster Analysis of Price Digits

\begin{tabular}{cccccccc}
\hline \multicolumn{2}{c}{ Panel A: Silver Market - First Digit to Right of Decimal } & & & \\
\hline & \multicolumn{2}{c}{ Futures Open } & \multicolumn{2}{c}{ Futures Close } & \multicolumn{2}{c}{ London PM } & \multicolumn{2}{c}{ Benford's } \\
Digit & \multicolumn{2}{c}{ Digit Percent } & \multicolumn{2}{c}{ Digit Percent } & Digit Percent & Caw \\
\hline & $1 / 2 / 2008$ & $8 / 15 / 2014$ & $1 / 2 / 2008$ & $8 / 15 / 2014$ & $1 / 2 / 2008$ & $8 / 15 / 2014$ & Cent Digit \\
& to & to & to & to & to & to & Distribution for \\
0 & $8 / 14 / 2014$ & $6 / 27 / 2018$ & $8 / 14 / 2014$ & $6 / 27 / 2018$ & $8 / 14 / 2014$ & $6 / 27 / 2018$ & Price $<100$ \\
1 & 8.97 & 9.10 & 9.40 & 8.58 & 9.95 & 10.56 & 10.17844 \\
2 & 9.34 & 10.67 & 10.32 & 11.61 & 9.34 & 10.36 & 10.13760 \\
3 & 10.44 & 11.61 & 9.83 & 11.82 & 9.58 & 10.36 & 10.09722 \\
4 & 9.71 & 9.52 & 10.20 & 9.73 & 11.48 & 10.88 & 10.05729 \\
5 & 9.77 & 10.15 & 11.48 & 10.77 & 8.79 & 9.52 & 10.01781 \\
6 & 10.32 & 12.13 & 8.91 & 10.46 & 8.85 & 9.62 & 9.978758 \\
7 & 8.85 & 9.52 & 9.40 & 9.10 & 10.62 & 9.62 & 9.940131 \\
8 & 11.11 & 7.32 & 10.32 & 10.56 & 10.93 & 10.04 & 9.901921 \\
9 & 10.74 & 9.62 & 10.87 & 8.37 & 10.87 & 9.21 & 9.864118 \\
$\chi^{2}$ & 10.74 & 10.36 & 9.28 & 9.00 & 9.58 & 9.83 & 9.826716 \\
Probability & 9.1429 & 15.6109 & 9.2039 & 13.0167 & 12.6838 & 2.4100 & 0.9832 \\
\end{tabular}


Panel B: Gold Market - First Digit to Left of Decimal

\begin{tabular}{|c|c|c|c|c|c|c|c|c|c|}
\hline Digit & \multicolumn{2}{|c|}{$\begin{array}{l}\text { Futures Open } \\
\text { Digit Percent }\end{array}$} & \multicolumn{2}{|c|}{$\begin{array}{l}\text { Futures Close } \\
\text { Digit Percent }\end{array}$} & \multicolumn{2}{|c|}{$\begin{array}{c}\text { London PM } \\
\text { Digit Percent }\end{array}$} & \multicolumn{2}{|c|}{$\begin{array}{c}\text { London AM } \\
\text { Digit Percent }\end{array}$} & \multirow{2}{*}{$\begin{array}{c}\text { Benford's } \\
\text { Law } \\
\text { Dollar Digit Distribution } \\
\text { For Price }>999\end{array}$} \\
\hline & $\begin{array}{c}1 / 2 / 2008 \\
\text { to } \\
3 / 19 / 2015\end{array}$ & $\begin{array}{c}3 / 20 / 2015 \\
\text { to } \\
6 / 27 / 2018\end{array}$ & $\begin{array}{c}1 / 2 / 2008 \\
\text { to } \\
3 / 19 / 2015\end{array}$ & $\begin{array}{c}3 / 20 / 2015 \\
\text { to } \\
6 / 27 / 2018\end{array}$ & $\begin{array}{c}1 / 2 / 2008 \\
\text { to } \\
3 / 19 / 2015\end{array}$ & $\begin{array}{c}3 / 20 / 2015 \\
\text { to } \\
6 / 27 / 2018\end{array}$ & $\begin{array}{c}1 / 2 / 2008 \\
\text { to } \\
3 / 19 / 2015\end{array}$ & $\begin{array}{c}3 / 20 / 2015 \\
\text { to } \\
6 / 27 / 2018\end{array}$ & \\
\hline 0 & 9.38 & 8.48 & 10.28 & 9.23 & 8.98 & 10.10 & 8.98 & 8.35 & 10.01760 \\
\hline 1 & 10.73 & 8.73 & 8.64 & 8.48 & 8.14 & 11.60 & 9.77 & 10.97 & 10.01369 \\
\hline 2 & 9.94 & 9.48 & 11.24 & 8.85 & 9.38 & 10.85 & 10.62 & 8.60 & 10.00977 \\
\hline 3 & 10.00 & 11.22 & 9.15 & 11.47 & 10.45 & 9.35 & 11.07 & 10.60 & 10.00585 \\
\hline 4 & 9.94 & 11.10 & 11.19 & 11.10 & 9.72 & 11.47 & 12.66 & 12.34 & 10.00194 \\
\hline 5 & 10.11 & 10.10 & 9.49 & 8.98 & 12.20 & 9.48 & 9.60 & 11.60 & 9.998028 \\
\hline 6 & 10.17 & 10.60 & 10.51 & 10.97 & 10.79 & 10.60 & 9.66 & 9.98 & 9.994124 \\
\hline 7 & 11.24 & 9.98 & 9.55 & 10.97 & 10.68 & 8.98 & 10.11 & 10.35 & 9.990224 \\
\hline 8 & 9.27 & 11.35 & 10.90 & 10.47 & 9.77 & 8.85 & 9.21 & 9.48 & 9.986328 \\
\hline 9 & 9.21 & 8.98 & 9.04 & 9.48 & 9.89 & 8.73 & 8.31 & 7.73 & 9.982437 \\
\hline$\chi^{2}$ & 6.5198 & 8.1247 & 14.2486 & 8.8479 & $19.7966^{*}$ & 8.3990 & $23.8192^{* *}$ & 15.6808 & \\
\hline Probability & 0.6870 & 0.5216 & 0.1138 & 0.4514 & 0.0192 & 0.4945 & 0.0046 & 0.0739 & \\
\hline \multicolumn{10}{|c|}{ Panel C: Gold Market - First Digit to Right of Decimal } \\
\hline \multirow{4}{*}{ Digit } & \multicolumn{2}{|c|}{ Futures Open } & \multicolumn{2}{|c|}{ Futures Close } & \multicolumn{2}{|c|}{ London PM } & \multicolumn{2}{|c|}{ London AM } & Benford's \\
\hline & \multicolumn{2}{|c|}{ Digit Percent } & \multicolumn{2}{|c|}{ Digit Percent } & \multicolumn{2}{|c|}{ Digit Percent } & \multicolumn{2}{|c|}{ Digit Percent } & Law \\
\hline & $\begin{array}{l}1 / 2 / 2008 \\
\text { to }\end{array}$ & $\begin{array}{c}3 / 20 / 2015 \\
\text { to }\end{array}$ & $\begin{array}{l}1 / 2 / 2008 \\
\text { to }\end{array}$ & $\begin{array}{c}3 / 20 / 2015 \\
\text { to }\end{array}$ & $\begin{array}{l}1 / 2 / 2008 \\
\text { to }\end{array}$ & $\begin{array}{c}3 / 20 / 2015 \\
\text { to }\end{array}$ & $\begin{array}{l}1 / 2 / 2008 \\
\text { to }\end{array}$ & $\begin{array}{c}3 / 20 / 2015 \\
\text { to }\end{array}$ & $\begin{array}{c}\text { Cent Digit Distribution } \\
\text { For Price }>999\end{array}$ \\
\hline & $3 / 19 / 2015$ & $6 / 27 / 2018$ & $3 / 19 / 2015$ & $6 / 27 / 2018$ & $3 / 19 / 2015$ & $6 / 27 / 2018$ & $3 / 19 / 2015$ & $6 / 27 / 2018$ & \\
\hline 0 & 16.61 & 15.09 & 11.58 & 8.85 & 38.81 & 15.09 & 37.01 & 12.72 & \\
\hline 1 & 9.21 & 8.85 & 8.47 & 9.10 & 0.06 & 8.10 & 0.11 & 8.48 & \\
\hline 2 & 9.89 & 10.97 & 10.51 & 10.22 & 14.24 & 11.85 & 16.44 & 10.72 & \\
\hline 3 & 8.64 & 9.85 & 10.06 & 9.23 & - & 7.48 & 0.06 & 8.98 & Virtually \\
\hline 4 & 8.31 & 6.86 & 8.02 & 11.10 & - & 9.35 & 0.17 & 9.35 & Uniform \\
\hline 5 & 11.64 & 12.34 & 12.32 & 9.85 & 31.92 & 12.97 & 26.95 & 9.98 & \\
\hline 6 & 8.25 & 8.98 & 9.27 & 10.47 & 0.06 & 8.60 & 0.17 & 9.60 & \\
\hline 7 & 8.47 & 9.35 & 9.60 & 10.60 & 14.86 & 10.47 & 18.81 & 12.72 & \\
\hline 8 & 10.06 & 10.47 & 10.62 & 9.85 & 0.06 & 8.85 & 0.28 & 8.73 & \\
\hline 9 & 8.93 & 7.23 & 9.55 & 10.72 & - & 7.23 & - & 8.73 & \\
\hline$\chi^{2}$ & $103.1525^{* * *}$ & $42.4140^{* * *}$ & $27.7062^{* *}$ & 4.1097 & $1883.7232^{* * *}$ & $47.8005^{* * *}$ & $2563.0780^{* * *}$ & $18.0249^{*}$ & \\
\hline Probability & $<.0001$ & $<.0001$ & 0.0011 & 0.9040 & $<.0001$ & $<.0001$ & $<.0001$ & 0.0349 & \\
\hline
\end{tabular}

Note: $* * * \mathrm{p}<0.001, * * \mathrm{p}<0.01, * \mathrm{p}<0.05$ 
Summary of Price Cluster Analysis Results

Overall, the findings from the price cluster analysis suggest some type of structural change in pricing distribution after the fix changes. Though not present across all gold and silver related markets, there is some evidence that prices more closely follow a Benford distribution after the fix changes, and this is especially true in the silver spot market.

\section{Conclusion}

The London spot price "fix" in gold and silver markets recently changed with the goal of greater market transparency and trader participation. Allegations of price manipulation have been made in the past, so the impact of this fundamental change in how prices are determined is important to understand. This paper studies the impact of these changes through simple means tests, rank tests, regressions, difference-in-difference modeling, and price clustering analysis.

The results show that returns have been unaffected by the recent changes in the fixing processes, but volatilities in the futures and various spot markets are lower in the post-fix change period that spans approximately 3.5 years. However, after controlling for the time trend of generally decreasing overall futures market volatility throughout the sample period, further examination of the relationship between the futures market and the London spot market suggests that the fix change significantly increased volatility of prices in silver and gold markets, respectively. Additional clustering analysis of price digits also suggests a change in price behaviors following the fix change. Collectively, the findings suggest some level of price manipulation prior to the fix change has since been dampened in the post-fix change period.

Out findings in the paper are perhaps as expected. A primary goal of the change in the fixing process in silver and gold markets was to both provide greater transparency and to expand the number of participants in the fixing process. These changes have appeared to reduce the level of observed price manipulation in silver and gold markets. The lessons from this study may be generalizable to other financial markets that currently suffer from a limited number of participants and/or high levels of opaqueness.

\section{References}

Abrantes-Metz, R. M. and Addanki, S. (2007). Is the market being fooled? An error-based screen for manipulation. SSRN Working Paper Series.

Abrantes-Metz, R. M., Froeb, L. M., Geweke, J., \& Taylor, C. T. (2006). A variance screen for collusion. International Journal of Industrial Organization, 24(3), 467-486.

Abrantes-Metz, R. M., Kraten, M., Metz, A. D., \& Seow, G. S. (2012). Libor manipulation? Journal of Banking \& Finance, 36(1), 136-150.

Abrantes-Metz, R. M., Villas-Boas, S. B., \& Judge, G. (2011). Tracking the Libor rate. Applied Economics Letters, 18(10), 893899.

Arnold, A. J. (2015). Business returns from gold price fixing and bullion trading on the interwar London market. Business History, 58(2), 283-308.

Batten, J. A., Lucey, B. M., \& Peat, M. (2016). Gold and silver manipulation: What can be empirically verified? Economic Modelling, 56, 168-176.

Bolotova, Y., Connor, J. M., \& Miller, D. J. (2008). The impact of collusion on price behavior: Empirical results from two recent cases. International Journal of Industrial Organization, 26(6), 1290-1307.

Burne, K., Day, M., \& Shumsky, T. (2013, March 14). U.S. probes gold pricing. The Wall Street Journal, Eastern edition; New York, N.Y., pp. A1.

Caminschi, A., \& Heaney, R. (2014). Fixing a Leaky Fixing: Short-Term Market Reactions to the London PM Gold Price Fixing. Journal of Futures Markets, 34(11), 1003-1039.

CME Group. (2017). Timeline of CME Achievements - CME Group. Retrieved October 7, 2017, from https://www.cmegroup.com/company/history/timeline-of-achievements.html.

CME Group (2018), CME Group leading products - Most traded futures and options contracts: Q2 2018. Retrieved October 15, 2018, from https://www.cmegroup.com/education/files/cme-group-leading-products-2018-q2.pdf.

Drudi, F., \& Massa, M. (2005). Price Manipulation in Parallel Markets with Different Transparency*. Journal of Business, 78(5), 1625-1658.

Garman, M. B., \& Klass, M. J. (1980). On the Estimation of Security Price Volatilities from Historical Data. Journal of Business, $53(1), 67$.

Genesove, D., \& Mullin, W. P. (2001). Rules, Communication, and Collusion: Narrative Evidence from the Sugar Institute Case. American Economic Review, 91(3), 379-398. 
Hauptfleisch, M., Putniņš, T. J., \& Lucey, B. (2016). Who Sets the Price of Gold? London or New York. Journal of Futures Markets, 36(6), 564-586.

Kumar, P., \& Seppi, D. J. (1992). Futures Manipulation with “Cash Settlement.” Journal of Finance, 47(4), 1485.

Liu, S.-M., \& Chou, C.-H. (2003). Parities and Spread Trading in Gold and Silver Markets: A Fractional Cointegration Analysis. Applied Financial Economics, 13(12), 899-911.

London Bullion Market Association. (2017). LBMA. Retrieved August 21, 2017, from http://www.lbma.org.uk.

London Bullion Market Association. (2020a). LBMA - Clearing Statistics. Retrieved June 29, 2020, from http://www.lbma.org.uk/clearing-statistics.

London Bullion Market Association. (2020b). LBMA - LBMA Gold Price. Retrieved June 29, 2020, from http://www.lbma.org.uk/lbma-gold-price.

London Bullion Market Association. (2020c). LBMA - LBMA Silver Price. Retrieved July 20, 2020, from http://www.lbma.org.uk/lbma-silver-price.

London Precious Metals Clearing Limited. (2017). LPMCL. Retrieved September 22, 2017, from http://www.lpmcl.com/.

Lucey, B. M., Larkin, C., \& O’Connor, F. A. (2013). London or New York: where and when does the gold price originate? Applied Economics Letters, 20(8), 813-817.

Nilsson, L. (2015). Did the new fix, fix the fix - an intraday exploration of the precious metal fixing. SSRN Working Paper Series.

Pirrong, C. (2017). The economics of commodity market manipulation: A survey. Journal of Commodity Markets, 5, 1-17.

Rice, X. (2014, April 14). Gold: In search of a new standard. Financial Times. Retrieved September 11, 2017, from https://www.ft.com/content/e31b0f44-b0e5-11e3-bbd4-00144feab7de.

(C) 2020 by the authors. Licensee ACRN Publishing, Austria, Editor in Chief Prof. Dr. Othmar M. Lehner. This article is an open access article distributed under the terms and conditions of the Creative Commons Attribution (CC BY SA) license (https://creativecommons.org/licenses/by-sa/4.0/) 